\title{
Adult social exploration in the rat as a function of pre- and post-weaning social experience'
}

MICHAEL STEVENSON, KANSAS STATE UNIVERSITY, MANHATTAN, KANSAS EDWARD C. SIMMEL, MIAMI UNIVERSITY, OXFORD, OHIO

The effects of pre-and post-weaning social isolation from litter mates on social exploration were investigated in the albino rat. The most important variable affecting S's stimulus preferences appeared to be its social experience immediately prior to testing. Isolated animals showed no preferences for any of the animal stimuli used, while socially experienced $S_{s}$ preferred a novel hooded rat. These results were interpreted as supporting the hypothesis that social exploration in the rat, as compared with mice or chickens, is more a function of novelty than gregarious behavior.

Studies of social choice and social exploration have established that various social experiences will affect performance differently in different species. Chickens (Pattie, 1936; Candland, Nagy, \& Conklyn, 1963; Candland \& Milne, 1966) and mice (Denenberg, Hudgens, \& Zarrow, 1964; Nagy, 1965) both prefer those social stimuli with which they are familiar. Rats, on the other hand, show a preference for unfamiliar rather than familiar animals (Tolman, 1961; Casey, 1962).

The present experiment was designed to study the affects of pre- and post-weaning social isolation on social stimulus preferences in the rat. If rats are in fact responding to unfamiliarity and novelty, then by manipulating previous social experience, the novelty value of a stimulus can be varied.

Subjects

The Ss were 20 male and 14 female Sprague-Dawley strain albino rats randomly divided into two groups at two days of age. Animals were either socially isolated from litter mates (I) or reared with litter mates (E). Each group was further divided into two subgroups when weaned at 20 days of age: Subgroup II $(\mathrm{N}=8)$ and EI $(N=9)$ were socially isolated, Subgroup IE $(N=7)$ were placed with 3-4 Ss from Group 1, and Subgroup EE $(N=10)$ were left with litter mates. The four groups thus consisted of animals isolated from litter mates during both the pre- and post-weaning period (II), animals having social experience throughout the experiment $(E E)$, animals deprived of peer interactions before weaning but given this experience post-weaning (IE), and animals having pre-weaning social experience with litter mates but isolated after weaning (EI).

Apparatus and Procedure

From birth until testing visual contact between cages was prevented by a translucent lining around individual cages, and by a gray curtain around the rack of cages itself.

At day 65 animals were tested for social preference in a semi-open field measuring 36 in. $x 38$ in. (see
Fig. 1). A start box 6 in. $x 4$ in. $x 7$ in. was located at one end of the field. A clear plexiglas guillotine door separated the start box from the rest of the field. At the opposite end, located outside of the apparatus itself, were spaced the four individual retaining cages which contained the social stimuli. These measured $6-1 / 2$ in. $x \quad 6-1 / 2$ in. $x 5$ in. and were separated from the field by $1 /$, in. hardware cloth to permit limited physical contact between $S$ and the stimuli. Located over each retaining cage was a 7-W frosted bulb which constituted the only illumination in the room. A half-circle on the floor with a 2 in. radius in front of each cage was designated as the "contact space." The set of three partitions located in the center of the field were used to prevent $S$ from persistently running down one side or the other, while avoiding the open space.

During test trials $S$ could choose between a likesex Sprague-Dawley albino rat of approximately the same age and weight, a Long Evans hooded rat which met the same criteria, a Sprague-Dawley weanling rat of like sex and from 20-30 days of age, and a rubber doll. The Ss were run on three consecutive days, one trial each day. Each stimulus animal was randomly selected from a pool of animals for any $S$ on any trial, and was not used on consecutive trials. Order of the stimuli was randomly assigned for each $\mathrm{S}$, but no

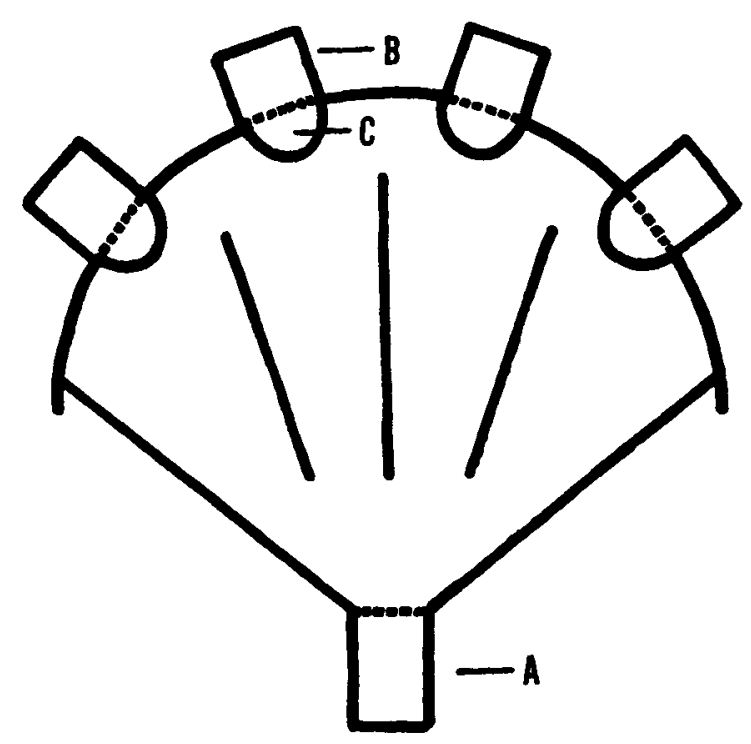

Fig. 1. Floor plan of social choice apparatus, showing location of (A) start box, (B) stimulus retaining cages, and (C) contact zones. 
S had the same ordering during his three trials. The response measure was the length of time spent by each $\mathrm{S}$ with the front half of the body in a particular "contact space" during the three 10-min. trials. This was recorded by E using an Esterline-Angus event recorder.

\section{Resulis}

Corrected for unequal group size (Winer, 1962), an analysis of variance of the total time spent exploring the stimuli as a function of social experience and sex indicated a significant main effect due to pre-weaning experience $(F=4.81, \mathrm{df}=1 / 26, \mathrm{p}<.05)$; rats reared with litter mates explored the stimulus objects significantly more than Ss reared only with their mothers.

In order to test for different stimulus preferences, uninfluenced by an S's total exploration score, scores for each stimulus were converted into percentage of total exploration. A four-way repeated measures factorial was run according to Krumbein \& Tukey (1956), with the variables being pre-weaning experience, postweaning experience, sex, and stimulus objects. A significant effect of stimulus objects was found $(F=9.06$, df $=3 / 78, p<.01$ ). Specific comparisons using Duncan's Multiple Range Test corrected for unequal number of replications (Kramer, 1956), showed that the hooded rat was significantly preferred over all other stimuli ( $p<.01)$, while the adult and weanling albinos were preferred over the inanimate object $(p<.10)$, but did not differ from each other.

A significant three-way interaction was found for stimulus objects by pre- by post-weaning experience ( $F=2.97, d f=3 / 78, p<.05$ ) while the two-way interaction of stimulus objects by post-weaning experience approached significance $(F=2.38, d f=3 / 78, p<.08)$. Specific comparisons indicated that these interactions were almost entirely a function of post-weaning social experience. Post-weaning isolation (Groups II and EI) resulted in no differences in response to any of the animal stimuli, while post-weaning experience with other Ss (Groups EE and IE), resulted in the hooded rat being explored significantly more $(p<.05)$ than any other animal. Only in the case of Ss isolated from litter mates since birth (Group II) did the inanimate object elicit significantly less responses $(p<.05)$ than the other stimuli.

\section{Discussien}

The most important variable affecting an animal's stimulus preferences appeared to be its social experience Immediately prior to testing (post-weaning experience). Recently isolated animals (Groups II and EI), which had been deprived of all social stimuli, showed no preferences for any of the animal stimuli, indicating perhaps that they were all equally novel. However socially experienced Ss (Groups EE and IE) preferred the hooded rat. This was the only rat in the testing situation with which they had had no previous contact, and thus could be considered the most novel social stimulus animal. Casey (1962) found similar results by isolating animals for only $70 \mathrm{hr}$. prior to testing in adulthood, thus indicating that our results were not due to long term deprivation but rather to a recency effect.

An animal's pre-weaning experience appeared to have no affect on its later social preferences. This was most likely due to the intervening post-weaning social conditions prior to testing, rather than to a lack of early environmental influence. Tolman (1961) for example, found that 22-day old rat pups could discriminate individuals of their own species and preferred unfamiliar over familiar animals. This suggests that perhaps early isolation would be affective in changing social stimulus novelty, if animals were tested at weaning.

\section{References}

Candland, D. K., \& Milne, D. Species differences in approachbehavior as a function of developmental environment. Anim. Behav., 1966, 14, 539-545.

Candland, D. K., Nagy, M., \& Conktyn, D. H. Emotional behavior in the domestic chicken (white leghorn) as a function of age and developmental environment. J. comp. physiol. Psychol., 1963, 56, 1069-1073.

Casey, A. Gregarious behavior in the rat as a function of secondary reinforcement, drive, and novelty. Unpublished doctoral dissertation, University of Kansas, 1962.

Denenberg, V. H., Hudgens, G. A., \& Zarrow, M. X. Mice reared with rats: Modification of behavior by early experience with another species. Science, 1964, 143, 380-381.

Kramer, C. Y. Extension of multiple range tests to group means with unequal numbers of replications. Biometrics, 1956, 12, 307-310.

Krumbein, W. C., \& Tukey. ,J. W. Multivariate analysis of mineralogic, lithologic, and chemical composition of rock bodies. $J$. sediment. Petrol., 1956, 26, 322-337.

Nagy, Z. M. Effect of early environment upon later social preference in two species of mice. J. comp. physiol. Psychol., 1965, 60, 98-101.

Pattie, F. A. The gregarious behavior of normal chicks and chicks hatched in isolation. J. comp. Psychol., 1936, 21, 161-178.

Tolman, C. W. Social preferences in the albino rat pup. Psychol, Rep., 1961, 8, 522.

Winer, B. J. Statistical principles in experimental design. New York: McGraw-Hill, 1962.

\section{Note}

1. This study is based on data collected as part of the M. A. Thesis of the first author, under the supervision of the second author at California State College at Los Angeles. It was read in part at the Midwestern Psychological Association meeting, Chicago, 1966 